\title{
CYANOGENIC POLIMORPHYSM IN BRACKENS, Pteridium arachnoideum AND P. caudatum, FROM THE NORTHERN ANDES
}

\author{
Alberto de J. Oliveros-Bastidas* e Miguel E. Alonso-Amelot \\ Departamento de Química, Facultad de Ciencias, Universidad de Los Andes, Mérida 5101, Venezuela
}

Recebido em 27/10/09; aceito em 3/4/10; publicado na web em 9/8/10

\begin{abstract}
Cyanogenesis in Pteridium caudatum and P. arachnoideum has been examined. Samples of the Andes of South America furnished

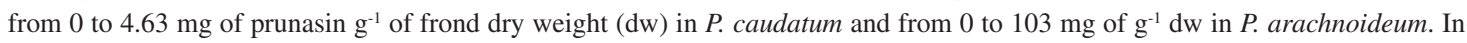
both fern species the continuous distribution of prunasin suggested cyanogenic polymorphism. The frequency of cyanogenic morphs was $84.7 \%$ for $P$. caudatum and $98.6 \%$ for $P$. arachnoideum. Cyanogenic activity was highest in the young crozier and waned rapidly with frond growth. The crozier head was found to yield HCN much more than the stipe.
\end{abstract}

Keywords: cyanogenesis; Pteridium; prunasin.

\section{INTRODUCTION}

Among the plant secondary metabolites capable to participate in trophic interactions, cyanogenic glycosides (CNGs) stand out as one of the xenobiotic materials most widely distributed in nature. Over 2500 plant species, ferns, gymnosperms and angiosperms alike, produce around of 70 different structures of these compounds. ${ }^{1}$ CNGs are also present in the animal kingdom; some millipedes and insects, ${ }^{2-7}$ that can synthesize or sequester them, and use these compounds against predators when disturbed or attacked, suggesting the involvement of CNGs in multitrophic interactions and their ancient origin. $^{7}$ The profusion of reviews, comprehensive articles and critical assessments that appear regularly in the literature attest to the importance given to this family of pro-toxins or phytoanticipins. ${ }^{8}$ The cyanogenic potential (ie. the amount of HCN released from cyanogenic glycosides) varies widely between species and between individuals within a species, ${ }^{9}$ characteristic defined as cyanogenic polymorphism. While some species appear to be monomorphic for cyanogenesis, ${ }^{10}$ most species studied have at least some acyanogenic individuals, and as such are truly polymorphic. ${ }^{11}$ Species such as Manihot esculenta, which have low and high cyanogenic forms, have close relatives that are acyanogenic.

CNGs may have multiple roles in the producing organism. Their function as defense materials, on the one hand, has been proposed repeatedly in light of their ability to produce toxic hydrogen cyanide $(\mathrm{HCN})$. The ecological role of CNGs is underscored by the apparent metabolic cost involved, as illustrated by the greater survival rates of acyanogenic morphs of Trifolium repens in the absence of significant herbivory ${ }^{12}$ and their better resistance to frost damage. ${ }^{13}$ The accepted tenet of the evolution of such materials in many organisms posits that bitter CNGs themselves or hydrogen cyanide produced from their enzymatic catabolism, when tissue is crushed or chewed, must be involved primarily in plant-herbivore interactions. ${ }^{14-16}$ Other CNGs breakdown compounds may have deleterious activities of their own. ${ }^{17}$ On the other hand, CNGs also serve as nitrogen-storage compounds that may be mobilized and catabolized under the nutritional requirements of the developing plant. ${ }^{18}$

Among ferns, examples of cyanogenesis are known. For example, young bracken (Pteridium ssp., Dennstaedtiaceae) fronds in Britain have been found to produce exceptionally as much as $50 \mu \mathrm{g} \mathrm{g}^{-1} \mathrm{dry}$

\footnotetext{
*e-mail: aloliver@ula.ve
}

weight (dw) of $\mathrm{HCN}^{19}$ stemming from its only $\mathrm{CNG}$, prunasin. Only one $\mathrm{HCN}$-producing material has been found in bracken: prunasin. ${ }^{20}$ The content of prunasin is wide variable in brackens. This amount decreases with the growing season, ${ }^{20-22}$ the frequency of cyanogenic genotypes is genetically determined, ${ }^{23}$ there is variation within plant; while rhizomes appear to accumulate a minimal amount of prunasin, fronds and rachis contain the largest quantity. ${ }^{24}$ In addition, in isolated reports the contents of prunasin has been associated with the structure of the insect community on bracken but results were not clear. ${ }^{25}$

Tropical brackens have not been examined in terms of their CNG content or cyanogenic polymorphism and capacity of $\mathrm{HCN}$ production. In northern South America there are two Pteridium species, $P$. caudatum (L.) Maxon and $P$. arachnoideum (Kaulf.) Maxon which are altitudinally segregated. ${ }^{25}$ The first thrive predominantly between the sea level and $2300 \mathrm{~m}$ above sea level with exceptional stands in protected habitats beyond this altitude, whereas $P$. arachnoideum grows in dense thickets preferably above $1800 \mathrm{~m}$ and as high as $3200 \mathrm{~m}$ just below the night frost line. As $P$. caudatum is a tetraploid hybrid of $P$. arachnoideum and a second undetermined parent, ${ }^{26,27}$ it may have developed traits more akin with the tropical conditions prevailing at lower altitudes around Caribbean countries, whereas $P$. arachnoideum, which is also distributed across the mountainous regions of South America and into colder countries such as Argentina, may have retained traits more adequate for the subtropical conditions of those extensive habitats. ${ }^{28}$ Only a comparative study of the two species may provide information in this context. The Presena study aims to evaluate the cyanogenic activity in Pteidium caudatum and $P$. aracnoideum. Therefore, this work was aimed at studying cyanogenesis systematically both neotropical brackens in terms of: determining the frequency of cyanogenic morphs; quantitizing the content of prunasin with frond growth; its variation with blade part, and determining the relative time dependent release of $\mathrm{HCN}$ of the crozier parts of one of the species. The results are discussed in terms of their ecological implications.

\section{EXPERIMENTAL}

\section{Sampling of bracken}

$P$. arachoideum fronds were collected from 8 different sites, situated between 1800 and $2600 \mathrm{~m}$ above sea level whereas eleven locations at elevations from 1100 to $2100 \mathrm{~m}$ served as sources of the 
P. caudatum accessions. P. caudatum voucher specimens were deposited in the New South Wales Botanical Gardens in Sydney, Australia under the care of Prof. J. Thomson, and numbered NSW 361276 and NSW 505771 and $P$. arachnoideum accessions were numbered NSW 361275 and NSW 505770.

All sites were located between $8^{\circ} 32^{\prime}$ to $8^{\circ} 42^{\prime} \mathrm{N}$ and $70^{\circ} 45^{\prime}$ and $71^{\circ} 35^{\top} \mathrm{W}$ in Mérida State, Venezuela, a generally mountainous area where bracken infestation is frequent. All samplings were performed during the rainy season, between late March and June of 1997, 1999 and 2003. Twelve to 18 fronds, depending on growth stage, were collected at each location, by cutting the stipe at ground level. In tropical environments where monthly temperature ranges are much less variable than in temperate latitudes the plant growth season is more tied to the rain regime than to the month of the year. Sampling was performed well after the onset of rains (late March in our geographical area) to prevent possible effects on the secondary chemistry of bracken caused by drought stress. For this part of the study frond development was separated in five stages: $1^{\text {st }}$ sage, crozier without ramification of pinnae and no visible follicles (Figure 2S, supplementary material); $2^{\text {nd }}$ stage, only lower pair of pinnae open with clearly visible follicles, while the upper pinnae remain unfolded; $3^{\text {rd }}$ stage, the two lower pairs appear fully unfolded and the upper pinnae still unfolding with immature follicles; $4^{\text {th }}$ stage, fully developed blade with still soft lax tips; $5^{\text {th }}$ stage, fully developed blade with hardened tissue and no signs of senescence (Figure 1S, supplementary material). To obtain a representative number of samples, $140 P$. arachnoideum blades from 8 locations and $134 P$. caudatum fronds from 11 different sites were analyzed in the picrate-based gas flow apparatus. All samples were first and second growth stage blades in view of the much lower content of cyanide in older blades.

Samples were stored in plastic clip bags in a cold box and brought to the laboratory within a few hours. In order to obtain adequate homogeneity of the sample, all pinnae from the first pair up were excised along the rachis in a left-right manner alternatively to form one first group. A second set was similarly composed with the remaining pinnae. The first group of excised pinnae was weighed fresh and its moisture content determined by heating at $100{ }^{\circ} \mathrm{C}$ until constant weight. The other group was used for chemical analysis as described below. Obviously, croziers could not be treated in this manner and were used whole. Their moisture content was determined in 10 separate fiddleheads collected at the same site.

\section{Analysis of prunasin content}

The second group of pinnae for chemical analysis described above was divided in 3 inch pieces by cutting only at the base of the pinnulae rachis with a fine razor to cause the least destruction of tissue and prevent the release of HCN. Enough pieces were then picked up randomly to yield sufficient material for analysis $(2-15 \mathrm{~g})$ and placed together immediately into a $125 \mathrm{~mL}$ ehrlenmeyer flask. Enough toluene to smear all surfaces of the plant material $(250-500 \mu \mathrm{L})$, was added to elicit HCN production. Earlier control experiments ${ }^{27}$ showed no significant differences between toluene elicitation and crushing to promote complete decomposition of prunasin into $\mathrm{HCN}$. Immediately after toluene addition, the Erlenmeyer flask was then inserted in a modified ${ }^{27}$ gas flow apparatus and the evolved $\mathrm{HCN}$ was quantified by its bubbling through an alkaline sodium picrate solution for $20 \mathrm{~h}$ at room temperature as described previously, ${ }^{27}$ using purified $\mathrm{NaCN}$ as standard. Addition of a $\beta$-glucosidase solution $(0.2 \%, \mathrm{pH}$ $5.5)$ to sand-macerated frond tissue after $20 \mathrm{~h}$ did not elicit further evolution of HCN. The content of prunasin was obtained from the molecular weight ratio of prunasin/ $\mathrm{HCN}$, the measured $\mathrm{HCN}$ and the sample dry weight.

\section{Cyanide content and frond part}

Second stage blades were selected for this part of the study. Seventeen $P$. arachnoideum fronds collected at one site at $1850 \mathrm{~m}$ were separated in two sections: the lower first pair of fully unfolded pinnae on the one hand, and the whole of the upper, unfolded stems, on the other.

\section{Time-dependent release of $\mathrm{HCN}$}

A fiddlehead of $P$. arachnoideum was divided in three parts: the head comprising only the meristem from the first axila upwards; the upper half of the stipe; and the lower half of the stipe. Each weighed fresh part was subject to maceration with cold sand $\left(-15^{\circ} \mathrm{C}\right)$ with mortar and pestle at the same temperature for $3 \mathrm{~min}$. The cold mass was transferred to a plastic tube immersed in a water bath $(30.0 \pm 0.1$ ${ }^{\circ} \mathrm{C}$ ) connected to the gas-flow apparatus, and the evolved $\mathrm{HCN}$ was carried into a picrate trap. Aliquots were drawn from this solution at regular intervals (20 min) for $180 \mathrm{~min}$ and the concentration of $\mathrm{HCN}$ was determined as above. Several croziers of the same size collected in the same area were cut into similar parts and each one was used for moisture content as described above. Results were assumed to be similar to the fiddleheads used for chemical analysis. P. arachoideum fiddlehead was divided into three sections: the head just below the first axila, the upper half of the stipe, and its lower 50\% down to the ground level. Two variables were determined in each section: total cyanogenic content and the time dependent release of $\mathrm{HCN}$ after tissue crushing with sand at $30.0 \pm 0.1{ }^{\circ} \mathrm{C}$.

\section{Reagents and apparatus}

Sodium bicarbonate (J. T. Baker Chemical Co.) and picric acid (BDH Laboratory Reagents) were used without further purification. Sodium cyanide (J. T. Baker Chemical Co.) was purified by recrystallization from degassed water-methanol-dichloromethane solutions. Absorbances of sodium picrate-cyanide complex were determined using a Hewlett-Packard (Palo Alto, California) Vectra UV-Vis 8453 spectrophotometer controlled by a Vectra-Pentium I Workstation.

\section{Statistical calculations}

Data were analyzed with ANOVA tests of comparison of the means, and t-test and chi-square test, which were performed using Statistix V 7.0 package, Analytical Software, St. Paul, Minnesota. For curve fitting and plotting Origin Professional software package V 5.0, Microcal Software, Northampton, Massachussetts, was used.

\section{RESULTS}

\section{Frequency and distribution of cyanogenic morphs}

Average prunasin levels in the pinnae ranged from 0 to $103 \mathrm{mg}$ $\mathrm{g}^{-1} \mathrm{dw}$ (mean \pm standard deviation $=11.983 \pm 18.521$ ) in $P$. arachnoideum whereas a much lower value was recorded for $P$. caudatum, ranging from 0 to only $4.63 \mathrm{mg} \mathrm{g}^{-1} \mathrm{dw}$ (mean \pm standard deviation $=0.897 \pm 1.149$ ). Tropical plants appear to be more stressed by invertebrate herbivory than those from temperate climates, due to greater insect species diversity and their year round presence. The ensuing pressure finds a response, for example, in the frequency of cyanogenesis (Thomsen and Brimer, 1997). Croziers of P. arachnoideum and P. caudatum in the northern Andes appear to respond to this general pattern by their sole prunasin content, which collectively taken display a continuous trend, and the elevated frequency of the cyanogenic genotype. Under the environmental constraints of these habitats, most of the population within the sampling universe of this 
study (>70\%) synthesize and store $15-40 \mathrm{mg} \mathrm{g}^{-1} \mathrm{dw}$ of prunasin, and some individual croziers contain in excess of $100 \mathrm{mg} \mathrm{g}^{-1} \mathrm{dw}$. When only cyanogenic croziers of both species were compared (Table 1) a clear difference between the cyanogenesis levels in $P$. caudatum vs. $P$. arachnoideum became apparent ( $t$-test, $p=0,02 ; n=40)$. It was also noticeable the continuous distribution of the cyanide content.

Table 1. Prunasin content ( $\mathrm{mg}$ Prunasin $\mathrm{g}^{1} \mathrm{dw}$ ) in crozier of fiddleheads of two Neotropical bracken species, Pteridium arachnoideum and P. caudatum, collected from a total of 4 sites in the western Andes of Venezuela. $(N=40)$

\begin{tabular}{lcccccccc}
\hline Pteridium & \multicolumn{4}{c}{ arachnoideum } & \multicolumn{4}{c}{ caudatum } \\
\hline Population & A & B & C & D & A & B & C & D \\
Mean & 25.07 & 11.45 & 31.44 & 21.43 & 12.53 & 18.22 & 11.42 & 22.66 \\
SD & 14.36 & 1.52 & 9.66 & 3.51 & 9.48 & 4.52 & 7.12 & 6.52 \\
Minimum & 7.68 & 17.23 & 12.22 & 7.77 & 1.34 & 2.45 & 5.42 & 2.35 \\
Maximum & 59.96 & 22.74 & 63.45 & 42,33 & 32.26 & 32.11 & 42.5 & 31.23 \\
\hline
\end{tabular}

Population elevation $(\mathrm{m}$ above sea level $)=$ A: $1100 ;$ B: 1800; C: 2000; D: 2400

In P. Caudatum $84.3 \%$ of the morphs were cyanogenic, while in P. arahnoideum $98.6 \%$. No differences were found between the polymorphism cyanogena between the two species of Pteridium $\left(\chi^{2}=0.37\right.$, $d f=1, p=0,543)$. Most acyanogenic $P$. caudatum genets were obtained from stands growing at lower altitudes, as illustrated by two sites at 1100 and $1180 \mathrm{~m}$ where $100 \%$ of the 14 blades collected $\left(2^{\text {nd }}\right.$ stage, see below) tested negative in the sensitive picrate solution analysis.

\section{Cyanogenic content and location}

The collection sites varied in altitude and as a result, also in average air temperature. ${ }^{29}$ However all locations had in common the habitat characterized by exposed mountain slope grasslands on which the bracken thickets grow extensively. ${ }^{30}$ No samples from shaded areas were taken. Although the prunasin concentrations were found to vary at each site within an ample range ( $P$. arachnoideum croziers: means $18.604 \pm 12.840$ to $36.358 \pm 20.357 \mathrm{mg} \mathrm{g}^{-1} \mathrm{dw}, P$. caudatum fiddleheads: $1.095 \pm 1.292$ to $1.823 \pm 0.916 \mathrm{mg} \mathrm{g}^{-1} \mathrm{dw}$ ) the means between populations of the same species at distant sites remained statistically undifferentiated ( $P$. arachnoideum: ANOVA $F_{2,140}=2.050, p=0.1271$. . caudatum: $\left.F_{2,134}=1.350, p=0.269\right)$.

\section{Cyanogenic content and frond phenology}

There was a sharp drop in the cyanide content as frond development progressed. Both species show significant differences in content between phenological stages prunasin (ANOVA: P. caudatum: $F_{2,38}=32$, $p<0,0001$; P.arachnoideum: $\left.F 2,38=p<0,0001\right)$. This descent was more pronounced in $P$. arachnoideum as croziers contained over 10 times in average of this compound than P. caudatum fiddleheads. However, from the $2^{\text {nd }}$ stage onwards the prunasin concentrations leveled to comparable figures in both species (Figure 1). Yet, $4^{\text {th }}$ stage $P$. arachnoideum fronds tended to retain a higher degree of cyanide activity since in many $P$. caudatum fronds this capacity waned to undetectable levels, hence lowering the average value.

\section{Cyanide content and frond part}

Second stage blades were selected for this part of the study. Seventeen $P$. arachnoideum fronds collected at one site at $1850 \mathrm{~m}$ were separated in two sections: the lower first pair of fully unfolded pinnae on the one hand, and the whole of the upper, unfolded stems, on the other. Cyanide analysis furnished clearly differentiated figures

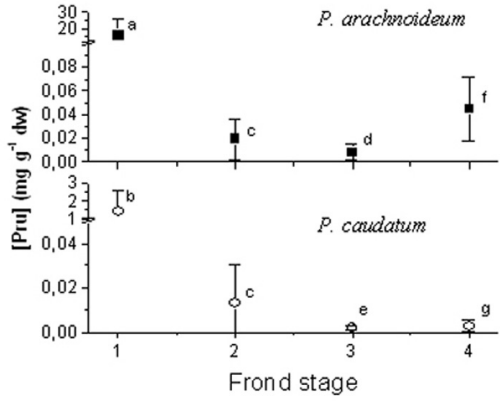

Figure 1. Variation in prunasin concentration with frond development in netropical P. arachnoideum and P. caudatum. Error bars are standard deviations of the means. Letters denote statistical comparisons (ANOVA) of each frond growth stage between the 2 bracken species. Equal letters indicate no statistical differentiation

with the upper portions of the blade possessing over three times the prunasin level of the lower section (Figure 2) $\left(A N O V A F_{2,19}=46.04\right.$, $p<0,001)$.

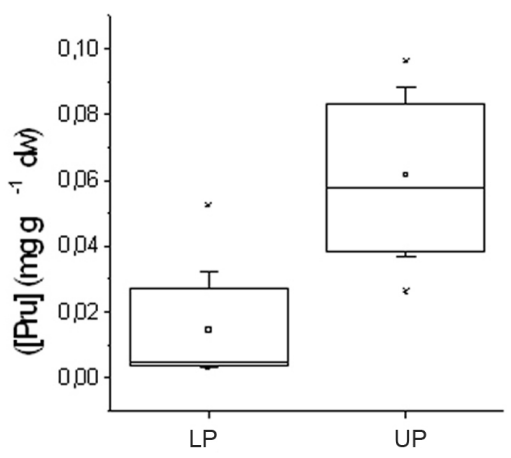

Figure 2. Box plot of the distribution of prunasin $\left(m g g^{-1} d w\right)$ in $2^{\text {nd }}$ stage blades of a neotropical stand of P. arachnoideum $(N=17) . \quad L P=$ lower pair of pinnae, $U P=$ upper portion of unfolding rachis. The square symbol within the boxes denotes the means of the data, the horizontal lines in the box indicate the $25^{\text {th }}, 50^{\text {th }}$, and $75^{\text {th }}$ percentile values. Error bars denote $5^{\text {th }}$ and $95^{\text {th }}$ percentile values

\section{Time dependent cyanide release and crozier parts}

As the previous experiments showed that cyanogenic concentrations rapidly waned while frond tissue hardened, it became of interest to explore the cyanogenic dynamics in a single growing crozier where a combination of soft and hardened tissue occurs. From the plots of accumulated HCN in the picrate trap vs. time (Figure 2) and the associated equations it was possible to calculate the initial velocity of natural cyanide formation from prunasin in each section. As Table 2 indicates, prunasin was concentrated chiefly in the crozier head, and this amount waned rapidly along the vertical transept of the stipe. This trend was followed by the initial velocities. Addition of a $\beta$-glucosidase solution $(0.2 \%)$ to the $\mathrm{HCN}$ exhausted material did not induce further evolution of cyanide. This could be interpreted as a double strategy of defence of bracken, suggest that the emerging fronds of $P$. arachnoideum possess the potential capacity, in terms of [Pru]t and rate of $\mathrm{HCN}$ formation, to embrace the two defense strategies, of a differential form in the tissues, accumulating a greater concentration of prunasin and speed of evolution of $\mathrm{HCN}$ in growing tissues and those most vulnerable to the plant, causing immediate feeding aversion in some herbivores, and preserving enough latent toxicity in its phytoanticipin form-prunasin-to cause damage inside the attacking organism. During growth, the bracken reduces nitrogen- 
based defense, and may increase carbon-based defenses such as tannins and phenolic derivatives. ${ }^{20}$ However, the balance of both defence routes in the overall $\mathrm{HCN}$-based defence of bracken will depend strongly on the feeding rate, amount ingested by the herbivore, and its digestive detoxification reactions, thus opening opportunities to herbivore specialization.

Table 2. Variation in prunasin concentration and initial velocity of HCN formation in three sections of a $P$. arachnoideum crozier. Initial velocities were obtained from the first degree coefficient of the linear, $2^{\text {nd }}$ or $3^{\text {rd }}$ degree polynomic regression of best mathematical fit of the data. $\mathrm{R}^{2}$ in parenthesis

\begin{tabular}{lcc}
\hline Crozier part & $\begin{array}{c}\text { Prunasin } \\
\left(\mathrm{mg} \mathrm{g}^{-1} \mathrm{dw}\right)\end{array}$ & $\begin{array}{c}\text { Initial velocity } \\
\left(\mu \mathrm{g} \mathrm{HCN} \mathrm{min} \mathrm{g}^{-1} \mathrm{dw}\right)\end{array}$ \\
\hline Head & 97.57 & $103.77 \pm 7.00(0.9972)$ \\
Upper half of stipe & 13.72 & $5.89 \pm 0.58(0.9914)$ \\
Lower half of stipe & 2.42 & $0.33 \pm 0.01(0.9985)$ \\
\hline
\end{tabular}

\section{DISCUSSION}

\section{Frequency and distribution of cyanogenica activity}

If the cost of synthesis and storage of some biologically active plant secondary metabolites can be associated with defense mechanisms against predation and/or infection, in the same measure the increment in frequency of genets expressing such active compounds in tropical habitats can be linked to a greater environmental stress there. In accordance with this tenet are the findings of increased frequency and abundance of plants bearing alkaloids as latitude decreases, ${ }^{31}$ the higher occurrence of cyanogenesis among plants in selected tropical areas ${ }^{32}$ and the frequency of cyanogenic morphs of Trifolium repens with isotherm zones in Europe during the winter months. ${ }^{33}$ The frequency of cyanogenic active types in the two Neotropical species of bracken here studied fit well with this general picture. The comparison between neotropical and paleartic bracken showed $>84 \%$ of cyanogenic positive genets among neotropical brackens vs only $3 \%$ in P. aquilinum from Britain ${ }^{33}$ it is clear response to this trend.

However, from consideration that $P$. arachonideum generally grows in colder areas where herbivore pressure is expected to be less than lower, hotter land where P. caudatum grows, some contradiction with the general trend becomes apparent. In the first place, if one compares the amount of cyanogenesis in the emerging fiddlehead of $P$. aquilinum from the British isles, which amounts to $0.55 \mathrm{mg} \mathrm{g}^{-1} \mathrm{dw},{ }^{34,35}$ with our results, it is clear that $P$. arachnoideum will surpass this figure over 100 times, but croziers of the more tropical type $P$. caudatum will accrue only marginally larger figures in many cases to the northern species. It is likely that not only herbivore pressure may have modeled evolutionary the plant cyanogenic response but other components may have had a significant contribution as well. Average temperatures associated with latitude have been related to the frequency of cyanogenic morphs of bracken [P. esculentum (Forst. F.) Cockayne] in Australia. A growing trend was observed in going from tropical Queensland in the north east (0\%), to New South Wales (13.6\%), to Victoria (46.2\%) near the southern end, and Tasmania (44\%) on the south coast. ${ }^{36}$ This is in agreement with the differences between $P$. caudatum and $P$. arachnoideum in both, frequency of $\mathrm{CN}$-active types and amount of prunasin stored in relation to their corresponding altitudinal tiers.

On the other hand, there are distinct differences in the growth rate of tropical bracken species. $P$. arachnoideum blades grow faster than $P$. caudatum fronds and mature into bigger blades in larger, denser thickets in most bracken stands. ${ }^{27,30,37}$ Prunasin, with its $4.75 \%$ of soluble nitrogen may contribute to the increased nutrient demands of faster growing $P$. arachnoideum, according to the mechanism suggested for Hevea brasiliensis seedlings. ${ }^{17,38}$ Such metabolic demands may supplement or even surpass the chemical defense needs imposed by local predation or infection.

It is clear from the prunasin content that both species are polymorphic, and an important number of the studied $P$. arachnoideum plants possess comparable quantities of prunasin to that in $P$. caudatum. Physiological needs rather than only defense demands may be implicated in the levels of prunasin observed, as one would surmise also from the relatively small variation in prunasin content in bracken from various sites that we recorded. That cyanogenesis is greater in growing parts of the blade also converges towards this concept. The incertitude exposed by Jones $1983^{39}$ that cyanogenesis is not only genetically determined but also environmentally plastic does not seem to proceed in tropical brackens, at least in our region under the constrains and possibilities of local soils and resources, and the limitations of a field experiment. Indeed, Low and Thomson ${ }^{37}$ found such environmental plasticity only in certain genotypes.

\section{Cyanogenesis and frond phenology}

The cyanogenic activity of developing blades of neotropical brackens follow the same trend observed for temperate ferns..$^{13,29}$ As the blade matures the concentration of prunasin drops rapidly to a minimal residual value (Figure 1). That this is so and not the consequence of a $\beta$-glucosidase abatement was ascertained by the addition of the enzyme after the HCN evolution had ceased in some of our cyanide-poor samples. The complementary experiment of adding prunasin to either non cyanogenic genets or even withering fronds of cyanogenic morphs and leading in fact to $\mathrm{HCN}$ evolution, clearly suggests the prevalence of the enzyme in all phenologic stages of the frond.$^{33}$ It is unclear whether the residual prunasin is still sufficient to elicit feeding deterrence in herbivores. In these advanced stages, blades also accumulate other deterrent metabolites such as phenolics and tannin in large quantity ${ }^{40}$ and no data exists on the combined contribution of these metabolites with prunasin to fend off herbivory.

\section{Prunasin content and frond part}

If the higher level of cyanide in the young frond and its sharp decrease as it matures could well be attributed to a defensive role of prunasin to protect valuable growing tissue, the accumulation of the CNG pool specially in the growing parts of fronds in a more advanced development stage, which we consistently observed in $P$. arachnoideum (Figure 2), appears to support this general view. Also the larger amounts of prunasin found in the crozier head and the considerably greater capacity to produce $\mathrm{HCN}$ per unit time (Figure 3 , Table 2 ) by the developing head -a parameter only rarely taken into consideration in plant cyanogenesis ${ }^{41}$ as compared with the hardening stipe leads to a similar conclusion. But it has been observed many times in other cyanogenic plants that new, rapidly growing tissue in meristems, buds, and seeds, where nitrogen demand is high, concentrate greater amounts of CNGs. Considering that these materials have been proven to function also as mobile nitrogen carriers ${ }^{38}$ and that these plant parts also require greater protection from herbivory in view of their softer consistency, greater content of nutrients, and intrinsic value to the developing plant, it becomes apparent that the combined roles of nutrient provider and chemical defense of CNGs such as prunasin result in an evolutionary advantage of considerable importance to the producer. Therefore, the synthesis, allocation and storage of these materials in a selective manner as in bracken, and their dynamic phenological behavior in combination with the rise of other chemical defense barriers ${ }^{28}$ is probably part of a complex balance between available resources and metabolic/defense needs of the developing blade and not only the result of predatory pressures. 


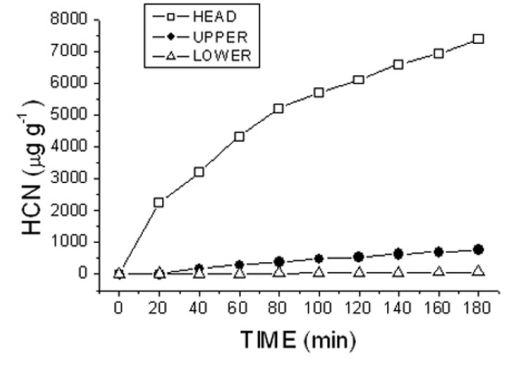

Figure 3. Time-dependent HCN evolution from crushed tissue of Pteridium arachnoideum crozier parts. Open squares: fiddlehead above the lower axila; filled circles: upper $50 \%$ of stipe; triangles: lower $50 \%$ of stipe

\section{SUPPLEMENTARY MATERIAL}

Available on http://quimicanova.sbq.org.br, in .PDF format, with free access.

\section{ACKNOWLEDGEMENTS}

We thank Magíster Scintae J. L. Avila (Universidad de Los Andes) for photographic assistance.

\section{REFERENCES}

1. Brinker, A.; Seigler, D. In Plant Toxin Analysis; Linskins, H. F.; Jackson, J. F., eds.; Springer-Verlag: Berlin, 1992, p. 359-381; Conn, E. In Herbivores, their interaction with secondary plant metabolites; Rosenthal, G. A.; Janzen, D. H., eds.; Academic Press: New York, 1979, p. 387-412; Conn, E. In The Biochemistry of Plants; Conn, E. E., ed.; Academic Press: New York, 1981, vol. 7, p. 479-500.

2. Nahrstedt, A.; Davis, R. H.; Biochem. Physiol. 1981, 68,575.

3. Nahrstedt, A.; Davis, R. H.; Comp. Biochem. Physiol. B 1983, 75, 65.

4. Davis, R.; Nahrstedt, A. In Comprehensive Insect Physiology, Biochemistry and Pharmacology; Veshut, G. A.; Gilbert, L. I., eds.; Pergamon Press: New York, 1984, vol. II, p. 198-221.

5. Nahrstedt, A.; Plant Syst. Evol. 1985, 150, 35.

6. Muhtasib, H.; Evans, D.; J. Chem. Ecol. 1987, 13, 133.

7. Nahrstedt, A.; Ciba Foundation Symp. 1988, 140, 131.

8. Schappert, P. J.; Shore, J.; J. Chem. Ecol. 1999, 25, 1455; Ellis, W.; Keymer, R.; Jones, D.; Experientia 1977, 33, 309; Conn, E. In The Biochemistry of Plants; Conn, E. E., ed.; Academica Press: New York, 1981, vol. 7, p. 479-500; Hruska, A.; J. Chem. Ecol. 1988, 14, 2213; Nahrstedt, A. In Cyanide Compounds in Biology; Evered, D.; Harnett, S., eds.; John Wiley \& Sons: Chichester, 1988, p. 131-150; Jones, D.; Phytochemistry 1998, 47, 155; Schappert, P.; Shore, J.; Ecoscience 1999, 6, 511; Magalhaes, C. P.; Xavier, J.; Campos, A.; Phytochem. Anal. 2000, 11, 57; Vetter, J.; Toxicon 2000, 38, 11; Zagrobelny, M.; Bak, S.; Rasmussen, A. V.; Jørgensen, B.; Naumann, C. ; Møller, B.; Phytochemistry 2004, 65, 293.
9. Till, I.; Heredity 1987, 59, 265; Hughes, M.; Sharif, A.; Dunn M.; Oxtoby, E. In Cyanide compounds in biology; Evered, D.; Harnett, S., eds.; John Wiley \& Sons: Chichester, 1988, p. 124-144; Jones, D. A. In Cyanide compounds in biology; Evered, D.; Harnett, S., eds.; John Wiley \& Sons: Chichester, 1988, p. 151-165.

10. McMahon, J.; White, W.; Sayre, R.; J. Exp. Botany 1995, 46, 731.

11. Pederson, G.; Fairbrother, T.; Greene, S.; Crop Sci. 1996, 36, 427.

12. Dirzo, L.; Harper, J.; J. Ecol. 1982, 70, 119.

13. Brighton, F.; Horne, M.; Nature 1977, 265, 437.

14. Jones, D. A. In Taxonomy and Ecology; Heywood, V. H., ed.; Academic Press: London, 1972, p. 213-242.

15. Jones, C. G. In Variable and Herbivores in Natural and Managed Systems; Denno, R. F.; McClure, M. S., eds.; Academic Press: New York \& London, 1983, p. 513-558.

16. Zagrobelny, M.; Bak, S.; Rasmussen, A.; Jørgensen, B.; Naumann, C.; Møller, B.; Phytochemistry 2004, 65, 293.

17. Vetter, J.; Toxicon 2000, 38, 11.

18. Moon, F.; Raafat, M.; J. Sci. Food Agric. 1951, 2, 327.

19. Cooper-Drive, G.; Swain, T.; Nature 1976, 26, 604.

20. Cooper-Driver, G.; Finch, S.; Swain T.; Bernays, E.; Biochem. Syst. Ecol. 1977, 5, 177.

21. Viette, M.; Tettamanti, C.; Saucy, F. J.; Chem. Ecol. 2000, 26, 101.

22. Kakes, P.; Euphytica 1990, 48, 25.

23. Thomsen, K.; Brimer, L.; Bot. J. Linn. Soc. 1997, 124, 273.

24. Kofod, H.; Eyjolfsson, R.; Tetrahedron Lett. 1966, 12, 1289.

25. Ortega, F.; J. Biollania 1990, 7, 47.

26. Thomson, J.; Alonso-Amelot, M.; Bot. J. Linn. Soc. 2002, 140, 237.

27. Alonso-Amelot, M.; Oliveros, A.; Phytochem. Anal. 2000, 11, 309.

28. Alonso-Amelot, M. In Studies in Natural Products Chemistry; Atta-urRahman., ed.; Elsiever: Pakistan, 2008.

29. Vetter, J.; Haraszti, E.; Agrokemia es Talajtan 1975, 24, 413.

30. Alonso-Amelot, M.; Rodulfo, S.; Vegetatio (Plant Ecol) 1996, 125, 137.

31. Robinson, T. In Herbivores, their interaction with secondary plant metabolites; Rosenthal, G. A.; Janzen, D. H., eds.; Academic Press: New York, 1979, p. 413-448.

32. Miller, R.; Jensen, R.; Woodrow, I.; Ann. Bot. 2006, 97, 1017.

33. Daday, H.; Heredity 1965, 20, 355.

34. Hadfield, P.; Dyer, A. In Bracken: Ecology, Land Use and Control Technology; Smith, R. T.; Taylor, R. T., eds.; Parthenon Press: Carnforth, 1986, p. 293-300.

35. Lawton, J.; J. Linn. Soc. 1976, 73,187.

36. Balik, M.; Furth, D.; Cooper-Driver, G.; Oecologia 1978, 35, 55.

37. Low, V.; Thomson, J. In Bracken Biology and Management; Smith, R. T.; Taylor, R. T., eds.; Australian Institute of Agricultural Science AIAS Occasional Publication $N^{\circ}$ 40: Wahroonga, New South Wales, 1990, p. 105-111.

38. Selmar, D.; Lieberei, R.; Biehl, B.; Plant Physiol. 1988, 86, 711.

39. Alonso-Amelot, M.; Oliveros-Bastidas, A.; Calcagno-Pisarelli, M.; Biochem. Syst. Ecol. 2004, 32, 969.

40. Goodger, J.; Capon, R.; Woodrow, I.; Biochem. Syst.Ecol. 2002, 30, 617. 
CYANOGENIC POLIMORPHYSM IN BRACKENS, Pteridium arachnoideum AND P. caudatum, FROM THE NORTHERN ANDES

Alberto de J. Oliveros-Bastidas* e Miguel E. Alonso-Amelot

Departamento de Química, Facultad de Ciencias, Universidad de Los Andes, Mérida 5101, Venezuela

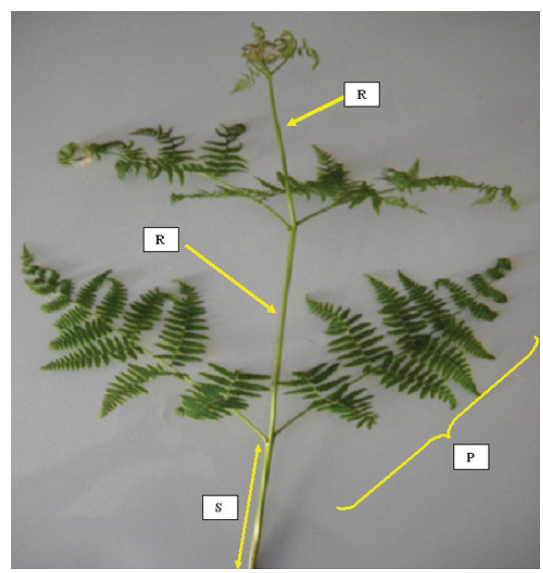

Figure 1S. Bracken frond (Pteridium aquilinum, Dennstaedtiaceae). P: Pinnae, R: Rachis, S: Stipe

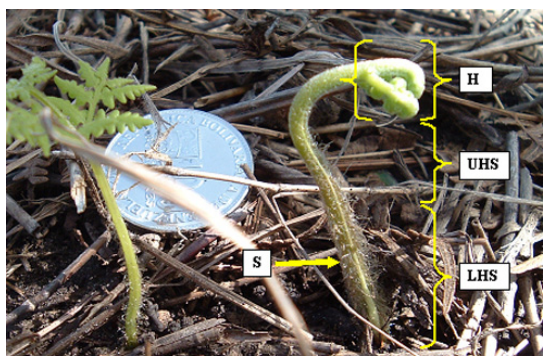

Figure 2S. Bracken crozier (Pteridium aquilinum, Dennstaedtiaceae). Three sections of crozier: H: Head; UHS: Upper half of stipe; LHS: Lower half of stipe; S: Stipe 